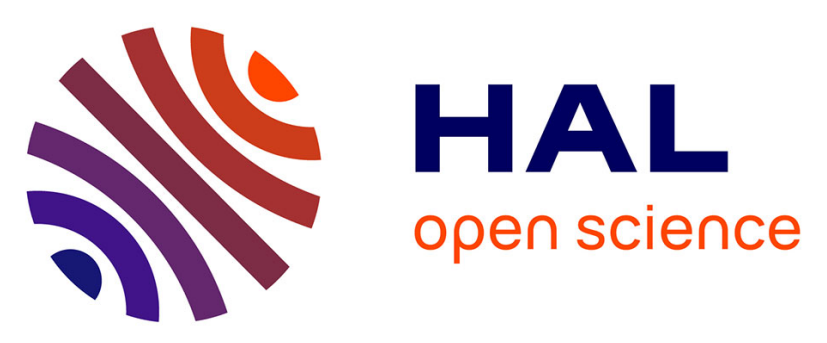

\title{
Europium(II) Compounds: Simple Synthesis of a Molecular Complex in Water and Coordination Polymers with 2,2'-Bipyrimidine Mediated Ferromagnetic Interactions
}

Gaël Zucchi, Pierre Thuéry, Eric Rivière, M. Ephritikhine

\section{To cite this version:}

Gaël Zucchi, Pierre Thuéry, Eric Rivière, M. Ephritikhine. Europium(II) Compounds: Simple Synthesis of a Molecular Complex in Water and Coordination Polymers with 2,2'-Bipyrimidine Mediated Ferromagnetic Interactions. Chemical Communications, 2010, 46, pp.9143. 10.1039/c0cc02539a . hal-00843060

HAL Id: hal-00843060

https://hal-polytechnique.archives-ouvertes.fr/hal-00843060

Submitted on 10 Jul 2013

HAL is a multi-disciplinary open access archive for the deposit and dissemination of scientific research documents, whether they are published or not. The documents may come from teaching and research institutions in France or abroad, or from public or private research centers.
L'archive ouverte pluridisciplinaire HAL, est destinée au dépôt et à la diffusion de documents scientifiques de niveau recherche, publiés ou non, émanant des établissements d'enseignement et de recherche français ou étrangers, des laboratoires publics ou privés. 


\title{
Europium(II) compounds: simple synthesis of a molecular complex in water and coordination polymers with $2,2^{\prime}$-bipyrimidine-mediated ferromagnetic interactions $\dagger$
}

\author{
Gaël Zucchi, ${ }^{a}$ Pierre Thuéry, ${ }^{a}$ Eric Rivière $^{b}$ and Michel Ephritikhine ${ }^{a}$ \\ Received 13th July 2010, Accepted 13th October 2010 \\ DOI: $10.1039 / \mathrm{c0cc02539a}$
}

\begin{abstract}
Reaction between $\mathrm{EuCl}_{2}$ and 2,2'-bipyrimidine (bpm) in de-oxygenated water afforded a cationic molecular complex $\left[\mathrm{EuCl}(\mathrm{bpm})_{2}\left(\mathrm{H}_{2} \mathrm{O}\right)_{4}\right][\mathrm{Cl}] \cdot \mathrm{H}_{2} \mathrm{O}$ (1). When performed in an organic solvent such as THF or methanol, the same reaction yielded a 3-dimensional coordination polymer of formula $\left[\mathrm{EuCl}_{2}(\mathrm{bpm})(\mathrm{MeOH})_{0.5}\right]_{\infty}(2)$ in which both $\mathbf{b p m}$ and the chloride ions act as linkers between the $\mathrm{Eu}(\mathrm{II})$ ions. Upon replacing $\mathrm{Cl}^{-}$by $\mathrm{I}^{-}$, two coordination polymers of formula $\left\{\left[\mathrm{Eu}(\mathrm{bpm})_{2}\left(\mathrm{H}_{2} \mathrm{O}\right)_{3}\right][\mathrm{I}]_{2}\right.$. $0.5 \mathrm{bpm}\}_{\infty}$ (3) and $\{[\mathrm{Eu}(\mathrm{I})(\mathrm{bpm})(\mathrm{MeOH})][\mathrm{I}]\}_{\infty}$ (4) were obtained from reaction in water and methanol, respectively. All these compounds were characterized by $\mathrm{X}$-ray crystallography. Investigations of the magnetic properties revealed a weak antiferromagnetic coupling in 2, while 3 and 4 showed a weak ferromagnetic coupling at low temperature.
\end{abstract}

Because of their reducing properties and sensitivity to air and moisture, divalent lanthanide complexes are generally handled under strictly anaerobic and anhydrous conditions. Therefore, most of the $\mathrm{Eu}(\mathrm{II})$ compounds were isolated from solid state reactions, ${ }^{1}$ or synthesized in liquid ammonia ${ }^{2}$ or organic solvents. ${ }^{3}$ A notable exception are the Eu(II) complexes with macrocyclic ligands such as crown ethers and cryptands, which are stable in deoxygenated water solutions; ${ }^{4}$ the greater stability of the divalent $v s$. trivalent complexes in this case was explained by the better fit of the larger $\mathrm{Eu}^{2+}$ ion within the macrocycle cavity and the relatively greater desolvation energy required for encapsulation of the more extensively aquated $\mathrm{Eu}^{3+}$ ion.

A great attention has recently been devoted to hybrid organicinorganic materials that result from the assembly of metal ions connected with organic ligands. Among these materials, those that can be prepared under mild conditions are of special interest. In view of the instability of europium in the divalent state, it is not surprising that such materials containing $\mathrm{Eu}^{2+}$ ions are not common. These are limited to a few solids obtained by sol-gel technology, ${ }^{5}$ in addition to the $1 \mathrm{D}$ coordination polymers ensured by chalcogenolate or cyanide bridges $\left[\mathrm{Eu}(\mathrm{TePh})_{2} \mathrm{NaTePh}(\mathrm{THF})_{2}\right]_{\infty}$ and $\left[\mathrm{Eu}(\mathrm{TePh})_{2}(\mathrm{THF})_{2}\right]_{\infty}{ }^{6}{ }^{6}$ $\left[\mathrm{Eu}\left(\mathrm{SC}_{6} \mathrm{~F}_{5}\right)_{2}(\mathrm{THF})_{2}\right]_{\infty}{ }^{7}$ and $\left[\mathrm{EuM}(\mathrm{CN})_{4}(\mathrm{DMF})_{4}\right]_{\infty}(\mathrm{M}=\mathrm{Ni}, \mathrm{Pt}){ }^{8}$

We detail herein the synthesis and the $\mathrm{X}$-ray crystal structures of three coordination polymers and one molecular complex

${ }^{a}$ CEA, IRAMIS, SIS2M, CNRS UMR 3299, CEA/Saclay,

91191 Gif-sur-Yvette, France.E-mail: gael.zucchi@cea.fr

${ }^{b}$ Université Paris-Sud, ICMMO - Equipe Chimie Inorganique,

UMR8182, 91405 Orsay, France

$\dagger$ Electronic supplementary information (ESI) available: Synthesis and crystallography measurement details, views of complexes 1, 2, and $\mathbf{3}$, and experimental details for the magnetic measurements. CCDC numbers 784445-784448. For ESI and crystallographic data in CIF or other electronic format see DOI: $10.1039 / \mathrm{c} 0 \mathrm{cc} 02539 \mathrm{a}$ comprising the $\mathrm{Eu}(\mathrm{II})$ ion and 2,2'-bipyrimidine obtained under soft experimental conditions. The magnetic properties of the hybrid materials are also reported.

Reaction of $\mathrm{EuCl}_{2}$ and $2 \mathrm{~mol}$ equiv. of bpm in deoxygenated water at room temperature led to the immediate formation of analytically pure dark brown crystals of $1 . \dagger$ The simple and straightforward synthesis of $\mathbf{1}$ is in striking contrast with that of the few other structurally characterized Eu(II) aquo complexes which have all been obtained by electrochemical reduction of Eu(III) precursors in the presence of carboxylates, ${ }^{9}$ crown ethers or cryptands. ${ }^{4}$ Among these complexes, [Eu(benzo-18-crown-6)$\left.\left(\mathrm{H}_{2} \mathrm{O}\right)_{3}\right]\left[\mathrm{ClO}_{4}\right]_{2}{ }^{10}$ and $\left[\mathrm{EuCl}\left(12\right.\right.$-crown-4) $\left.\left(\mathrm{H}_{2} \mathrm{O}\right)_{3}\right][\mathrm{Cl}]^{11}$ were the sole examples of poly-aquo mononuclear derivatives. The crystal structure of the cation of $\left[\mathrm{EuCl}(\mathrm{bpm})_{2}\left(\mathrm{H}_{2} \mathrm{O}\right)_{4}\right][\mathrm{Cl}] \mathrm{H}_{2} \mathrm{O}$ (1) is depicted in Fig. 1, together with those of the other compounds described in this paper. The nine coordinate $\mathrm{Eu}(\mathrm{II})$ ion is in a monocapped square antiprismatic environment, the two square bases $\mathrm{O}(1)-\mathrm{Cl}(1)-\mathrm{N}(5)-\mathrm{N}(6)$ and $\mathrm{O}(2)-\mathrm{O}(3)-\mathrm{O}(4)-\mathrm{N}(1)$ (rms deviations 0.13 and $0.05 \AA$ ) forming a dihedral angle of $1.98(16)^{\circ}$. The average Eu-N distance of 2.830(4) $\AA$ is larger than those we recently reported in the Eu(III) complexes $\left[\mathrm{Eu}\left(\mathrm{NO}_{3}\right)_{3}(\mathrm{bpm})_{2}\right]^{12}$ and $\left[\left\{\mathrm{Ln}(\mathrm{acac})_{3}\right\}_{2}(\mu-\mathrm{bpm})\right]^{13}$ (acac is acetylacetonato) where it amounts to 2.593(3) and 2.6278(16) §, respectively. This is in agreement with the variation in the radii of the $\mathrm{Eu}^{2+}$ and $\mathrm{Eu}^{3+}$ ions. ${ }^{14}$ The mean $\mathrm{Eu}-\mathrm{O}\left(\mathrm{H}_{2} \mathrm{O}\right)$ bond length of 2.599(3) $\AA$ is similar to that of 2.58(2) $\AA$ in [EuCl(12-crown-4)$\left.\left(\mathrm{H}_{2} \mathrm{O}\right)_{3}\right]^{+}$, while the $\mathrm{Eu}-\mathrm{Cl}$ bond distance of 3.0360(14) $\AA$ is larger than that of $2.879(5) \AA$ in the same compound.

When performed at room temperature in THF or $\mathrm{MeOH}$, the reaction of $\mathrm{EuCl}_{2}$ and 1, 2 or 4 mol equiv. of bpm resulted
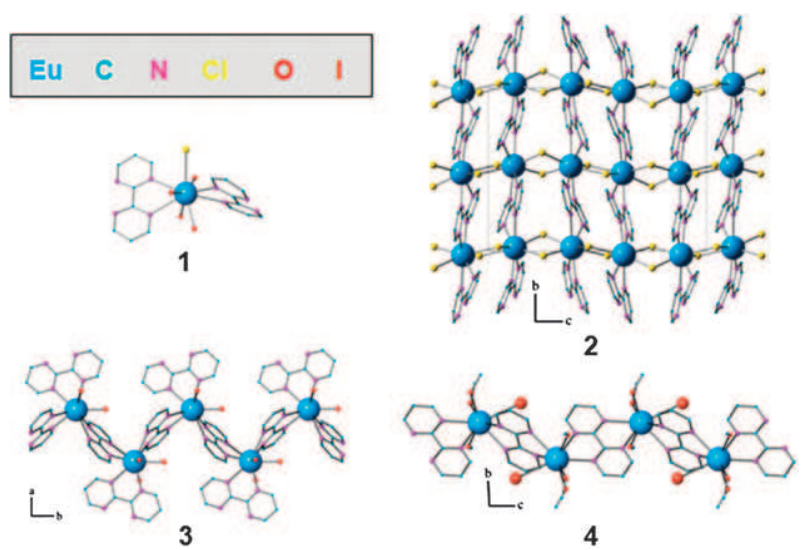

Fig. 1 Top: view of the cation of 1 (left) and view of the 3D network in 2 down the $a$ axis (right); bottom: views of the 1D polymers in 3 (left) and 4 (right). 
in the precipitation of a dark brown solid, and dark brown crystals of 2 were obtained in $81 \%$ yield (from the $1: 1$ reaction) after recrystallization from hot methanol. The asymmetric unit in the complex $\left[\mathrm{EuCl}_{2}(\mathrm{bpm})(\mathrm{MeOH})_{0.5}\right]_{\infty}$ (2) comprises two divalent europium ions, two bpm molecules, four chlorine atoms and one methanol molecule. Each europium ion is eight-coordinate, with four bridging chlorine atoms and four nitrogen atoms from two bridging bpm molecules, thus defining a square antiprismatic arrangement around the metal centre. The average $\mathrm{Eu}-\mathrm{N}$ and $\mathrm{Eu}-\mathrm{Cl}$ bond lengths are equal to $2.77(5)$ and $2.955(15) \AA$, respectively; these values are $0.05 \AA$ smaller than those measured in $\mathbf{1}$, reflecting the distinct coordination numbers. The solvent methanol molecule is hydrogen bonded to one of the chlorine atoms $[\mathrm{O}(1) \cdots \mathrm{Cl}(2)$ $3.189(5) \AA, \mathrm{O}(1)-\mathrm{H}(1) \cdots \mathrm{Cl}(2) 177^{\circ}$ ]. The two bpm molecules are nearly planar, with dihedral angles of $10.0(2)^{\circ}$ and $11.6(2)^{\circ}$ between the two rings. Some weak $\pi$-stacking interactions are present, with centroid...centroid distances of 3.93-3.95 dihedral angles of $23^{\circ}-30^{\circ}$ and centroid offsets of $1.08-2.11 \AA$. The two $\mathrm{Eu}_{2} \mathrm{Cl}_{2}$ motifs are nearly planar with rms deviations of 0.123 and $0.001 \AA$ for the $\mathrm{Cl}(1) \mathrm{Cl}(2)$ and $\mathrm{Cl}(3) \mathrm{Cl}(4)$ bridges, respectively, and the dihedral angle between the two units is $37.24(2)^{\circ}$. $\left\{\mathrm{EuCl}_{2}\right\}_{n}$ polymeric chains parallel to the $c$ axis are thus formed; these chains are further connected by the bridging bpm ligands so as to form a three-dimensional framework. Here again, the synthesis of $\mathbf{2}$ is very simple when compared with those of the other structurally characterized $3 \mathrm{D}$ coordination polymers of $\mathrm{Eu}(\mathrm{II})$, i.e. the electrochemical preparation of carboxylate complexes, ${ }^{9}$ the solid state synthesis of the organic-inorganic perovskite $\left[\mathrm{Eu}\left(\mathrm{C}_{4} \mathrm{H}_{9} \mathrm{NH}_{3}\right)_{2} \mathrm{I}_{4}\right]_{\infty}{ }^{15}$ and the solvothermal synthesis of the homoleptic framework of $\left[\mathrm{Eu}\left(\mathrm{C}_{5} \mathrm{H}_{4} \mathrm{~N}_{4}\right)_{2}\right]_{\infty} .{ }^{1}$ It was noted that the high temperatures required to obtain the latter compound could induce the fragmentation of the organic ligand and/or the oxidation of the divalent lanthanide ion, making the products difficult to predict and control. ${ }^{16}$ The network of $\mathbf{2}$ was broken in water, leading to the formation of the mononuclear aqua complex 1 which readily crystallized.

When performed with $\mathrm{EuI}_{2}$, the same reactions afforded the two coordination polymers $\left\{\left[\mathrm{Eu}(\mathrm{bpm})_{2}\left(\mathrm{H}_{2} \mathrm{O}\right)_{3}\right][\mathrm{I}]_{2} \cdot 0.5 \mathrm{bpm}\right\}_{\infty}$ (3) and $\left\{\left[\mathrm{Eu}(\mathrm{I})(\mathrm{bpm})(\mathrm{MeOH})_{3}\right][\mathrm{I}]\right\}_{\infty}$ (4) from water and methanol, respectively. The Eu(II) ion in $\mathbf{3}$ is nine-coordinate through three oxygen atoms from the water molecules, and six nitrogen atoms from three different bpm molecules. The two different coordination modes of the bpm molecule are found, since two molecules act as bridging ligands while the third is terminal. These two coordination modes were also observed for the trivalent lanthanide ions. ${ }^{12,17}$ The coordination polyhedron in 3 can be described as a monocapped square antiprism, the two square faces being $\mathrm{O}(1)-\mathrm{O}(2)-\mathrm{O}(3)-\mathrm{N}(6)$ (rms deviation $0.062 \AA$ ) and $\mathrm{N}(1)-\mathrm{N}(2)-\mathrm{N}\left(3^{\prime}\right)-\mathrm{N}\left(4^{\prime}\right)(0.014 \AA)$, respectively [dihedral angle $5.6(4)^{\circ}$ ], and $\mathrm{N}(5)$ being the capping atom. The average Eu-O distance is 2.598(15) $\AA$, while the $\mathrm{Eu}-\mathrm{N}$ distance amounts to $2.79(2) \AA$. The two bridging bpm molecules ensure the formation of a $1 \mathrm{D}$ polymer, with zigzag chains directed along the $b$ axis. In compound $\mathbf{4}$, the $\mathrm{Eu}(\mathrm{II})$ ion is coordinated by the oxygen atoms of three methanol molecules (average Eu-O distance 2.56(2) А), four nitrogen atoms belonging to two bpm molecules (average Eu-N distance of 2.726(11) $\AA$ ), and one iodide ion. The fact that only one iodide ion can coordinate the $\mathrm{Eu}(\mathrm{II})$ ion is in keeping with the larger size of this ion and its softer character, with respect to chloride ions. In this case also, the two bridging bpm molecules allow the formation of a 1D coordination polymer, with chains running along the $c$ axis.

The three coordination polymers described above in which the $\mathrm{Eu}(\mathrm{II})$ ions are connected via bpm and $\mathrm{Cl}^{-}$bridges are interesting candidates for magnetism investigations for the following main reasons. bpm was shown to afford electronic connections between transition metal ions, ${ }^{18-20}$ and, probably because of the high sensitivity of $\mathrm{Eu}(\mathrm{II})$ to oxidation, there exists no study on the magnetic behaviour of compounds comprising organic ligands and the divalent europium ion, despite the great potential of $\mathrm{Eu}(\mathrm{II})$ arising from its seven unpaired f electrons as far as magnetic properties are concerned. Only a very few examples of magnetic interactions between trivalent lanthanide ions connected by the bis-bidentate bpm ligand can be found in the literature. Recently, it has been reported that bpm led to an antiferromagnetic interaction between two $4 \mathrm{f}$ elements in dimers of $\mathrm{Gd}(\mathrm{III})^{21}$ and $\mathrm{Ce}(\mathrm{III}){ }^{22}$

Plots of the inverse of the molar susceptibility $v s$. temperature for 2, 3 and $\mathbf{4}$ at an applied field of $1 \mathrm{kOe}$ are shown in the inset of Fig 2. For the three compounds, the inverse of the susceptibility can be fit to the Curie-Weiss law; Weiss and Curie constants are reported in Table 1. The effective moment deduced from these values is in agreement with the presence of divalent europium (for which the theoretical free-ion magnetic moment is $7.9 \mu_{\mathrm{B}}$ ).

For compounds $\mathbf{3}$ and $\mathbf{4}, \chi T$ is constant at high temperature (not shown) and increases below $10 \mathrm{~K}$. This shows that ferromagnetic interactions occur (Fig. 2). Considering that 3 and 4 are chains of centres with $S=7 / 2$ which are equally spaced, the coupling constant $J$ can be derived from eqn (1): ${ }^{23}$

$$
\begin{aligned}
& \chi T=\frac{N g^{2} \beta^{2} S(S+1)}{3 k} \frac{1+u}{1-u} \\
& u=\operatorname{coth}\left[\frac{J S(S+1)}{k T}\right]-\left[\frac{k T}{J S(S+1)}\right]
\end{aligned}
$$

The best fit effectuated in the $2-40 \mathrm{~K}$ range leads to the following values: $J=0.02 \mathrm{~cm}^{-1}$ for $3\left(g=1.93, R=2.5 \times 10^{-5}\right)$ and

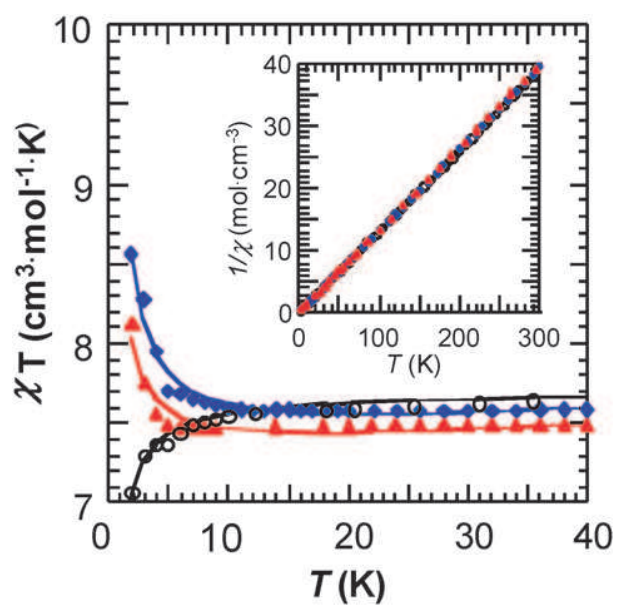

Fig. 2 Plot of $1 / \chi$ and $\chi T v$ s. temperature for compounds 2 (black), 3 (blue) and $\mathbf{4}$ (red). For $\chi T$ vs. temperature, solid lines were generated by the best fit parameters given in the text. 
Table 1 Weiss and Curie constants and effective moment for compounds $\mathbf{2}, \mathbf{3}$, and 4

\begin{tabular}{llll}
\hline & $\theta / \mathrm{K}$ & $C / \mathrm{cm}^{3} \mathrm{~mol}^{-1} \cdot \mathrm{K}$ & $\mu_{\mathrm{eff}} / \mu_{\mathrm{B}}$ \\
\hline $\mathbf{2}$ & -0.19 & 7.67 & 7.8 \\
$\mathbf{3}$ & +0.06 & 7.57 & 7.8 \\
$\mathbf{4}$ & +0.02 & 7.48 & 7.7 \\
\hline
\end{tabular}

$0.01 \mathrm{~cm}^{-1}$ for $4\left(g=1.92, R=3.5 \times 10^{-5}\right)$ with $R=\Sigma\left(\chi T_{\text {calc }}-\chi T_{\text {obs }}\right)^{2} / \Sigma\left(\chi T_{\text {obs }}\right)^{2}$.

Magneto-structural correlations in coupling between lanthanide atoms are not trivial. ${ }^{24}$ As indirect pathways are generally involved, the geometry of the bridge or the distance between the magnetic centres can have an influence on the magnitude or the sign of the magnetic coupling.

Here, these weak ferromagnetic coupling values are close, and the slight difference could have various origins, but, in a first approach, we will focus on the distances between two metal ions. For 3, 7.0427(6) A separate two Eu(II) centres of an equally spaced chain, whereas in $\mathbf{4}$, two different distances between $\mathrm{Eu}(\mathrm{II})$ can be distinguished within the same chain:

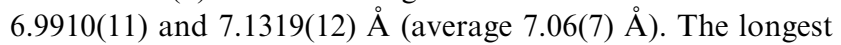
distance may weaken the ferromagnetic coupling. Ferromagnetic interaction in $\mathrm{Gd}^{3+}$ dimers or chains has been reported, ${ }^{25}$ but such ferromagnetic interaction between two metal centres connected by a bpm molecule is, to the best of our knowledge, unprecedented. In fact, this bis-chelating ligand has been shown to be useful for favouring antiferromagnetic interactions in systems of high nuclearity. ${ }^{26,27}$

The magnetic behavior of $\mathbf{2}$ in the $2-40 \mathrm{~K}$ temperature range is also shown in Fig. 2. Below $20 \mathrm{~K}, \chi T$ decreases, indicating that a weak antiferromagnetic coupling occurs. In this compound, two paths of exchange can be distinguished: the first one being through the bmp molecules (7.1022(5) and 7.1366(5) $\AA$, average $7.12(2) \AA$ ) which can mediate weak ferromagnetic coupling, and the second one through the chlorine bridging

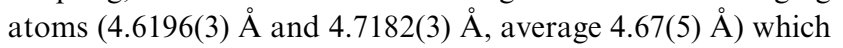
leads to the antiferromagnetic coupling. To simplify the model, as the Eu-bpm-Eu distance is longest than that in 4, the ferromagnetic interaction can be neglected. Thus, the same chain model can be used to quantify the antiferromagnetic interaction through the chlorine atoms. Eqn (1) gives: $J_{\mathrm{AF}}=-0.01 \mathrm{~cm}^{-1}\left(g=1.975, R=4.0 \times 10^{-6}\right)$.

In summary, we have reported the facile synthesis of a monometallic Eu(II) complex (1), the first ever obtained in de-oxygenated water without the use of electrochemical techniques and encapsulating ligands. We have also described the easy and rapid synthesis of the three coordination polymers $\mathbf{2}$, $\mathbf{3}$, and $\mathbf{4}$ obtained under soft conditions. The latter show different topologies due to the changes in counter ion and solvent and the two possible coordination modes of bpm. We have presented the first magnetism studies on compounds of $\mathrm{Eu}(\mathrm{II})$ coordinated with an organic ligand, which show that a ferromagnetic coupling could occur between two metal centres connected by bpm.

We thank the CEA and the CNRS for financial support.

\section{Notes and references}

1 (a) W. Liao, C. Hu, R. K. Kremer and R. Dronskowski, Inorg. Chem., 2004, 43, 5884; (b) K. Müller-Buschbaum, Y. Mokkadem, F. M. Schapper and R. Pöttgen, Angew. Chem., Int. Ed., 2007, 46, 4385.
2 (a) A. L. Wayda, I. Mukerji, J. L. Dye and R. D. Rogers, Organometallics, 1987, 6, 1328; (b) J. P. White III, H.-B. Deng and S. G. Shore, J. Am. Chem. Soc., 1989, 111, 8946; (c) C. D. Stevenson, T. Schertz and R. C. Reiter, J. Am. Chem. Soc., 1999, 121, 6964.

3 (a) W. J. Evans, J. L. Shreeve and J. W. Ziller, Inorg. Chem., 1994, 33, 6435; (b) G. W. Rabe, G. P. A. Yap and A. L. Rheingold, Inorg. Chem., 1997, 36, 3212; (c) W. J. Evans, M. A. Greci, M. A. Ansari and J. W. Ziller, J. Chem. Soc., Dalton Trans., 1997, 4503; (d) A. R. Strzelecki, C. L. Likar, B. A. Helsel, T. Utz, M. C. Lin and P. A. Bianconi, Inorg. Chem., 1994, 33, 5188; (e) S. R. Daly and G. S. Girolami, Inorg. Chem., 2010, 49, 4578; $(f)$ R. Jiao, X. Shen, M. Xue, Y. Zhang, Y. Yao and Q. Shen, Chem. Commun., 2010, 46, 4118.

4 (a) A. O. Gansow, R. A. Kausar, K. M. Triplett, M. J. Weaver and E. L. Yee, J. Am. Chem. Soc., 1977, 99, 7087; (b) J. Jiang, N. Higashiyama, K.-i. Machida and G.-Y. Adachi, Coord. Chem. Rev., 1998, 170, 1.

5 (a) M. Iwasaki, N. Sato, J. Kuraki and S. Ito, J. Sol-Gel Sci. Technol., 2000, 19, 357; (b) E. Cordoncillo, F. J. Guaita, P. Escribano, C. Philippe, B. Viana and C. Sanchez, Opt. Mater. (Amsterdam), 2001, 18, 309; (c) L. Raehm, A. Mehdi, C. Wickleder, C. Reyé and R. J. P. Corriu, J. Am. Chem. Soc., 2007, 129, 12636.

6 D. V. Khasnis, M. Brewer, T. Lee, T. J. Enge and J. G. Brennan, J. Am. Chem. Soc., 1994, 116, 7129.

7 J. H. Melman, T. J. Emge and J. G. Brennan, Inorg. Chem., 2001, 40, 1078.

8 D. W. Knoeppel and S. G. Shore, Inorg. Chem., 1996, 35, 5328.

9 (a) P. Starynowicz, Polyhedron, 1995, 14, 3573; (b) P. Starynowicz, J. Alloys Compd., 2000, 305, 117; (c) P. Starynowicz and G. Meyer, Z. Anorg. Allg. Chem., 2000, 626, 2441; (d) P. Starynowicz, Polyhedron, 2003, 22, 2761.

10 P. Starynowicz, K. Bukietyńska, S. Golab, W. Ryba-Romanowski and J. Sokolnicki, Eur. J. Inorg. Chem., 2002, 2344.

11 P. Starynowicz, Polyhedron, 2003, 22, 337.

12 G. Zucchi, O. Maury, P. Thuéry, F. Gumy, J.-C. G. Bünzli and M. Ephritikhine, Chem.-Eur. J., 2009, 15, 9686.

13 G. Zucchi, T. Jeon, D. Tondelier, D. Aldakov, P. Thuéry, M. Ephritikhine and B. Geffroy, J. Mater. Chem., 2010, 20, 2114.

14 R. D. Shannon, Acta Crystallogr., Sect. A: Cryst. Phys., Diffr., Theor. Gen. Crystallogr., 1976, 32, 751.

15 D. B. Mitzi and K. Liang, Chem. Mater., 1997, 9, 2990.

16 (a) K. Müller-Buschbaum and Y. Mokkadem, Eur. J. Inorg. Chem., 2006, 2000; (b) K. Müller-Buschbaum and Y. Mokkadem, Chem. Commun., 2006, 2060.

17 G. Zucchi, O. Maury, P. Thuéry and M. Ephritikhine, Inorg. Chem., 2008, 47, 10398.

18 O. Fabelo, J. Pasán, F. Lloret, M. Julve and C. Ruiz-Pérez, Inorg. Chem., 2008, 47, 3568.

19 N. Marino, T. F. Mastropietro, D. Armentano, G. De Munno, R. P. Doyle, F. Lloret and M. Julve, Dalton Trans., 2008, 5152.

20 Y. Rodríguez-Martin, J. Sanchiz, C. Ruiz-Pérez, F. Lloret and M. Julve, Inorg. Chim. Acta, 2001, 326, 20.

21 K. O. Znovjyak, O. V. Moroz, V. A. Ovchynnikov, T. Yu. Sliva, S. V. Shishkina and V. M. Amirkhanov, Polyhedron, 2009, 28, 3731 .

22 M. Koziez, R. Pezka, M. Rams, W. Nitek and B. Sieklucka, Inorg. Chem., 2010, 49, 4268.

23 O. Kahn, Molecular Magnetism, VCH, New York, 1993.

24 (a) L. E. Roy and T. Hughbanks, J. Am. Chem. Soc., 2006, 128, 568; (b) S. C. Manna, E. Zangrando, A. Bencini, C. Benelli and N. R. Chaudhuri, Inorg. Chem., 2006, 45, 9114.

25 (a) J.-P. Costes, J.-M. Clemente-Juan, F. Dahan and F. Nicodème, Dalton Trans., 2003, 1272; (b) S. T. Hatscher and W. Urland, Angew. Chem., Int. Ed., 2003, 42, 2862; (c) R. Baggio, R. Calvo, M. T. Garland, O. Peña, M. Perec and A. Rizzi, Inorg. Chem., 2005, 44, 8979; (d) L. E. Sweet, L. E. Roy, F. Meng and T. Hughbanks, J. Am. Chem. Soc., 2006, 128, 10193.

26 D. Armentano, G. de Munno, F. Guerra, J. Faus, F. Lloret and M. Julve, Dalton Trans., 2003, 4626 and references therein.

27 G. De Munno, M. Julve, F. Lloret, J. Faus, M. Verdaguer and A. Caneschi, Angew. Chem., Int. Ed. Engl., 1993, 32, 1046. 